\title{
An Analysis of Pandemic Panic Buying Motivators among Undergraduate College Students Using Mind Genomics Cognitive Science
}

\author{
Alexis Theriot, Natalia Urrutia-Alvarez, Erin M. McKinley \\ School of Nutrition and Food Sciences, Louisiana State University and the LSU AgCenter, Baton Rouge, LA, USA \\ Email: emckinley@agcenter.lsu.edu
}

How to cite this paper: Theriot, A., Urrutia-Alvarez, N., \& McKinley, E. M. (2021). An Analysis of Pandemic Panic Buying Motivators among Undergraduate College Students Using Mind Genomics Cognitive Science. Psychology, 12, 1457-1471. https://doi.org/10.4236/psych.2021.129092

Received: August 25, 2021

Accepted: September 26, 2021

Published: September 29, 2021

Copyright $\odot 2021$ by author(s) and Scientific Research Publishing Inc. This work is licensed under the Creative Commons Attribution International License (CC BY 4.0).

http://creativecommons.org/licenses/by/4.0/

\begin{abstract}
Introduction: Panic buying is a well-practiced behavior related to COVID-19 where individuals purchase food in greater quantity and speed due to emergency or feared lack of supply. Mind Genomics ${ }^{\mathrm{TM}}$ is the psychological science of analyzing decisional processes to identify true internal thoughts. The study aimed to map out the decisional processes of undergraduate students regarding panic buying, to reveal distinct segments of thinking. Methods: A cross-sectional, web-based survey was completed by 200 undergraduates enrolled at Louisiana State University in early 2021. The 30-item survey included questions on demographics, comfort, finances, COVID-19 diagnosis, and 16 literature-driven elements related to panic buying. Results: The majority white (79.6\%) samples fell into two mindsets. One mindset $(\mathrm{n}=$ 98) puts focus on nutrient content (i.e., fresh not frozen, long shelf life, only what is available for their diet) when buying food during COVID-19. A smaller subset $(n=65)$ has additional concern, buying what appears healthy and shopping to feel in control. The white students had significantly higher financial means $(p=.022)$ and higher comfort $(p<.001)$ than the Black students to shop and purchase food during COVID-19. Conclusion: When college students are faced with a pandemic, there is a large focus on nutrient content when buying food. It is important to reinforce students know how to find healthy foods that fit their diet. To better enable students to obtain nutritious foods, college health educators should help build good shopping habits while acknowledging that not all students have the same means to acquire what is needed.
\end{abstract}

\section{Keywords}

Panic Buying, Buying Motivators, College Students, COVID-19 


\section{Introduction}

Since January 2020, the novel coronavirus (COVID-19) has caused massive fundamental changes in the health, social, political, and economic landscape across the globe due to its global-spread contamination (Harizi, Trebicka, Tartaraj, \& Moskowitz, 2020). The hallmark of the pandemic has been staying at home and social distancing, which influences determinants of panic buying for needing food and supplies that may be in short supply. Panic buying is defined as the action of buying large quantities of a particular product or commodity due to sudden fears of a forthcoming shortage or price increase (Hornblower et al., 2012). This buying behavior is typically triggered by short-term, or one-time events, such as a severe storm or a temporary disruption in a supply-chain, but the COVID-19 pandemic included the element of an extensive length of time with most stay-at-home orders lasting 3 months or longer. This created a unique opportunity to evaluate panic buying motivators among individuals in the United States, where the COVID-19 pandemic infiltrated the country quickly whilst the public scrambled to not only understand the severity of the virus but to also prepare to be forced to stay at home for weeks at a time with very little notice.

Optimal behavioral science and panic-buying literature were reviewed to determine the chosen elements related to panic-buying. Elements based on nutrient content were determined from other published literatures, which indicated individuals possessing a COVID-19 risk factor purchased health and safety products at a higher rate than those not perceiving to have any risk for the virus (Clemens, Matkovic, Faasse, \& Geers, 2020). Buying what appears to be healthy could be a motivator behind such actions, as it could be a means to cope with the stress of a health pandemic by attempting to improve one's health or immunity. Buying only what is available for one's diet to maintain a "normal" lifestyle is another possible way to cope (Dickins \& Schalz, 2020). Brugarolas, Martinez-Carrasco, Rabadan, and Bernabeu (2020) found that "consumers tend to focus on amount of product versus quality of product and tend to be more accepting of high prices if amount is secured." Having the ability to buy as high of a quantity that is available at one time may be a motivator behind panic buying, as well as grabbing items that are easy and fast to carry out. Actual purchase choices tend to depend on availability and any quantity restrictions. Less time to shop due to set restrictions correlated with less time spent processing information about products. Elements based on concern of quantity and price were also found in the literature (Martin-Neuninger \& Ruby, 2020). Elements based on personal feelings and emotions were derived from studies illustrating panic buying as a response to the lack of control of the future and the impact this lack has on stress levels. People engage in specific behavior patterns in reaction to this emotional distress, such as buying more than usual (Lins \& Aquino, 2020). Shopping out of fear the stores will run out of needed items, which is another noted motivator (Martin-Neuninger \& Ruby, 2020).

Elements surrounding environmental factors were rooted in concerns about 
the availability of food in grocery stores that were open and within proximity, which led to an increase of purchasing activity. Geographic regions with little available food stores experienced short-term shortages of items and what was perceived by shoppers as "empty shelves" (Jezewska-Zychowicz, Plichta, \& Krolak, 2020). Feelings of having to be prepared for the worst, worrying about getting COVID-19, and feelings of one's susceptibility to infection were not improving throughout the pandemic in the areas where the panic buying was caused by the environmental crisis. Bonneaux and Van Damme (2006) found panic buying may be fueled by the desire to avoid feelings of regret later if purchases do not occur, including the worrying that other housemates or family members will not effectively shop for what is really needed. The research team, consisting of a Registered Dietitian with experience in shopping behaviors, took the liberty to add additional elements not previously found in the literature.

College students represent a unique population that was affected in unique ways by the pandemic. Most students were quickly uprooted from campus living quarters and asked to return home with only a few days' notice. All on-campus classes were quickly converted to $100 \%$ online learning utilizing new technologies not commonly used prior to that time. Students living in off-campus housing, but who relied on campus dining outlets to provide meals, were then on their own to secure groceries and fend for themselves. Food insecurity among college students is well studied and documented (Knol, Robb, McKinley, \& Wood, 2017; Morris, Smith, Davis, \& Null, 2016; Patton-López, López-Cevallos, Cancel-Tirado, \& Vazquez, 2014). Those students already experiencing food insecurity prior to the pandemic were more proportionately affected by campus and local food pantry closures. If a student did have a job, they may not have been deemed an essential worker and may have faced a decline in income depending on if they were able to file for unemployment benefits. The behavior of panic buying may have been occurring more among college students feeling the financial effects of the pandemic in addition to a short supply of open grocery outlets all with limited available inventory. The motivating factors for engaging in panic buying may be unique among college students during a pandemic than what has been described in the available literature on traditional panic buying. Using Mind Genomics ${ }^{\mathrm{TM}}$ to assess what college students think about when faced with the idea of a potential future shut-down or mandatory quarantine will allow researchers to essentially map out the ethereal decision-making pattern in the brain in a simple, non-invasive way to real major patterns or segments of thinking.

\section{Purpose}

To date, Mind Genomics ${ }^{\mathrm{TM}}$ study methods have not been utilized to look at the behavior of panic buying. Traditional MG studies have focused on product-specific marketing research to reveal true wants of consumers about a particular item such as a new food product or new marketing messages with which 
the buyer resonates. The purpose of this study was to map out the decision-making processes of undergraduate college students when faced with shopping for themselves, or their household, during a pandemic to reveal the segments of thinking (motivators) around panic buying. This is the first study of its kind to utilize MG and BimiLeap to evaluate panic buying motivators.

\section{Methods}

Mind Genomics ${ }^{\mathrm{TM}}(\mathrm{MG})$ is the psychological science of studying the decisional processes of people to identify what they really want to buy, wear, read, watch, etc. (Moskowitz, Gofman, Beckley, \& Ashman, 2006). It was introduced in the 1980's by Howard Moskowitz and is continued today through the company, MindCart AI, who train researchers on how to utilize MG study technology (the BimiLeap survey platform) and the statistics in an area of their choosing. To briefly explain Mind Genomics ${ }^{\mathrm{TM}}$, it is necessary to first explain conjoint measurement, which is a crucial element in the foundation of Mind Genomics ${ }^{\mathrm{TM}}$. Conjoint measurement analyzes reactions to combinations of ideas (rather than presenting ideas independently) to best understand what stimulates consumers. By presenting combinations of ideas, the experimental design simulates realistic scenarios, leading respondents to make trade-off decisions rather than a one-at-a-time yes or no decision. However, ideas can only contribute relative utility values due to statistical multicollinearity given the experimental design. Therefore, it is not possible to draw significant meaning from utility values (Moskowitz, et al., 2006). Howard Moskowitz sought to alleviate this handicap by beginning to develop what would become Mind Genomics ${ }^{\mathrm{TM}}$, a science aiming to take conjoint analysis to the next level by strengthening its ability to produce meaningful results.

Besides conjoint measurement, MG is founded on "the principles of stimulus-response (from experimental psychology), Internet-based testing (from marketing research), and multiple tests to identify patterns of Mind-Sets (patterned after Genomics)." Moskowitz developed a user-friendly survey platform called BimiLeap (Big Mind Learning App) out of the perceived necessity to have a "concrete" method that would allow anyone to conduct a MG study (Moskowitz, Wren, Papajorgji, \& Petraq, 2020). BimiLeap runs ordinary least-squares regressions for the user and provides the output with little burden on the researchers to run the statistics themselves. The provided output spreadsheet allows researchers to look at multiple variables including predisposition to the topic of interest, response time, and an open-ended question response. Most notably, however, the system's analysis reveals distinct "mindsets" of the population through cluster analysis.

\subsection{Survey Development}

A cross-sectional, web-based survey of 41 questions was created using both the Qualtrics and BimiLeap survey platforms. Due to limitations of the early version 
of the BimiLeap platform, Qualtrics was utilized to house 12 additional demographic questions and items pertaining to COVID diagnosis, comfort with shopping during the pandemic, financial means to shop during the pandemic, household size, residence type, and the responsible shopping party in the household. Every BimiLeap survey contains 29 questions that consist of one open-ended question, three demographic questions (sex, age range, and birthday), one 4-point agreement scale classification question, and 24 vignettes containing two to four of the original 16 literature-driven elements related to panic buying, each with a 5-point Likert-scale rating scale.

The final 16 elements that were integrated into the BimiLeap survey were chosen based on presence in the literature and strength of those study designs. It was determined the common motivators that tend to drive panic buying mainly revolved around four main areas: shopping for foods based on nutrient content, concern with quantity/servings/price, personal feelings, and environmental factors. These four areas became the four quadrants (A-D) of the MG portion of the study (Table 1). The quadrant A elements regarding nutrient content were: 1) buying fresh, not frozen, 2) buying foods with a long shelf life, 3) buying what appears to be healthy, and 4) buying only what is available for my diet. The quadrant B elements regarding quantity/servings/price were: 1) buying as high of a quantity that is available, 2) buying larger or family size packages, 3) getting the most I can within my budget, and 4) grabbing the items I can that are fast and easy to carry out. The quadrant $C$ elements regarding personal feelings were: 1 ) shopping because I am stressed out, 2) shopping because I feel out of control of the situation, 3) shopping because I am afraid the stores will run out of food, and (4) shopping because I need to feel more secure. The quadrant D elements regarding environmental factors were: 1) feeling COVID-19 is not getting better in my area, 2) feeling like I must always be prepared for the worst, 3) worrying that I am at risk for getting COVID-19, and 4) worrying that my roommates or family will not buy what is really needed.

\subsection{BimiLeap Survey Platform}

When connecting to the BimiLeap portion of the study, respondents were asked three demographic questions (sex, age range, and birthday) and further presented with the classification question, "How much do you agree with the statement. I bought groceries in a 'panic during the COVID-19 pandemic?" Answer options included: strongly agree, slightly agree, slightly disagree, and strongly disagree. Respondents were then exposed to the first of the series of 24 vignettes and directed to answer based on the following question, "Based on the ideas of the elements in the vignette below as a WHOLE, how likely were you to consider these when grocery shopping during COVID-19?” This question was repeatedly shown at each vignette exposure, each on a new screen after the previous vignette was scored. A 5-point Likert scale with 1 being "highly unlikely" and 5 being "highly likely" was utilized for these items. At no time are the respondents shown the names or foci of the quadrants. 
Table 1. Final four quadrants and corresponding sixteen elements tested to determine panic buying mindsets.

\begin{tabular}{ll}
\hline A: Nutrient Content & B: Quantity/Servings/Price \\
\hline A1: Buying fresh not frozen & B1: Buying as high of a quantity that is available \\
A2: Buying food with a long shelf life & B2: Buying larger or family size packages \\
A3: Buying what appears to be healthy & B3: Getting the most I can within my budget \\
A4: Buying what is available for one's diet & $\begin{array}{l}\text { B4: Grabbing the items I can that are fast and easy } \\
\text { to carry out }\end{array}$ \\
\hline $\begin{array}{l}\text { C: Personal Feelings } \\
\text { C1: Shopping because I am stressed out }\end{array}$ & $\begin{array}{l}\text { D1: Feeling COVID is not getting better in my } \\
\text { area }\end{array}$ \\
$\begin{array}{ll}\text { C2: Shopping because I feel out of control of } \\
\text { the situation }\end{array}$ & $\begin{array}{l}\text { D2: Feeling like I must always be prepared for the } \\
\text { worst }\end{array}$ \\
$\begin{array}{ll}\text { C3: Shopping because I am afraid the stores } \\
\text { will run out of food }\end{array}$ & $\begin{array}{l}\text { D3: Worrying that I am at risk for getting } \\
\text { COVID-19 }\end{array}$ \\
$\begin{array}{l}\text { C4: Shopping because I need to feel more } \\
\text { secure }\end{array}$ & $\begin{array}{l}\text { D4: Worrying that my roommates or family will } \\
\text { not buy what is really needed }\end{array}$ \\
\hline
\end{tabular}

The "vignettes," of ideas, or "elements" were composed by the researchers based on previous research on traditional panic buying. The elements were further organized into a $4 \times 4$ table (typical for MG studies) with 4 main categories, or "silos," each with 4 elements related to that category for a total of 16 elements. By nature of design, the BimiLeap system created combinations of the elements and presented the vignettes to respondents. No two respondents were exposed to the same identical set of 24 vignettes. This is since while the experimental design stays constant across respondents, a permutation in the system ensures that the actual combinations differ from one respondent to another (MindCartAI, 2021). The BimiLeap software is set to ensure that the vignettes are composed of $2-4$ elements, that only one element per silo will be incorporated into a vignette, and that the 16 elements will be statistically independent of each other. BimiLeap then links responses to the presence or absence of the independent elements, using ordinary least-squares regression. By doing this, BimiLeap determines the degree to which respondents identify with elements; this is known as "resonance" in MG terms. Resonance can be examined at the respondent level, but it is the hallmark of MG data interpretation to look at resonance after the cluster analysis is complete to view how the elements fit into the resulting mindset(s).

\subsection{Participants}

The final study population included a convenience sample of 200 undergraduate students enrolled at Louisiana State University in Baton Rouge, Louisiana, USA in the spring semester of 2021. Potential participants had to be at least 18 years of age and be enrolled at LSU as an undergraduate in the spring of 2021. No other inclusion or exclusion criteria were set. Undergraduate college students were chosen as the convenience sample for ease of survey distribution and study 
completion in the short 2-month time frame allotted by the undergraduate research grant received by the authors to complete the study. It was also found that literature on panic buying and motivators for panic buying is very limited among college students in the United States. This human subject's study was approved by the LSU AgCenter Institutional Review Board prior to survey distribution.

\subsection{Data Collection}

A small pilot study was conducted among 50 undergraduate students prior to this full study to test the survey for comprehensibility, survey time, and assessment of any technical difficulties. Participants were directed to Qualtrics first using a specific URL, then after answering the 12 items, were directed to click a specific link to connect to the BimiLeap survey system. The pilot study revealed the need to improve survey question wording for better participant understanding.

To recruit the 200 needed participants for the full study, researchers identified one class with the largest number of enrolled students and upon study approval, the professor was contacted to distribute the survey link to registered students. The sample was acquired in a general management studies online course with over 800 registered students. This course was chosen for both its size and the diverse subsets of students, such as major program of study and class year since the course is required by multiple degree programs across campus. Since the survey platforms were available 24 hours a day, the 200 survey completes were achieved in 3 days. Participants were not incentivized in any way for their time participating in the study. The sample size was set at 200 as BimiLeap studies are set up with a preset maximum sample size and researchers pay $\$ 2.00$ per survey completion, plus a $\$ 600$ set up fee. The grant funds used for this study totaled $\$ 1000$.

\subsection{Statistical Methods}

The data was analyzed by cluster analysis using case segmentation and ordinary least squares regressions to reveal the distinct segments of thinking with the top motivating elements and least motivating elements related to panic buying. BimiLeap produced an Excel data spreadsheet that was uploaded to SPSS for confirmation of the results and additional multiple regressions. A series of ANOVAs and t-tests were conducted among the demographic information collected in the Qualtrics items.

During analysis, BimiLeap transformed rating responses to a binary (0 or 100) scale following the standard approach of consumer researchers. If the respondent accepted a vignette, (selecting a rating of 4 or $5=100$ ), then they were a member of the "group." If the respondent was a vignette rejecter, (selecting a rating 1,2 , or $3=0$ ), then they were not a member of the "group." The rating scale cutoff is arbitrary, but this one is standard in MG studies due to its ability 
to yield accurate responses in prior studies (Moskowitz, 2012). Once the entire data set was analyzed, each element produced an average coefficient (utility) value, following the algorithm created by Moskowitz and Martin (2008). Based upon numerous studies of this type, norms for utility values have been developed. A utility value of 8 or above indicates the element is resonating with the population (Moskowitz \& Martin, 2008). BimiLeap aids researchers in identifying resonance by highlighting coefficients $\geq 8$ green.

Ordinary least squares (OLS) regressions first generated individual level models in preparation for clustering. It then ran with groups of respondents, defined by characteristics such as who they are (gender, age) and by how they thought about the topic (Moskowitz, 2018). OLS then divided the total sample: first, into 2 mindsets, then, into 3 mindsets. According to Moskowitz, the number of mindsets that is selected for observation should be based upon two criteria, the first being interpretability, meaning the strongest performing elements must "tell a coherent story." The second being parsimony, meaning the fewer mindsets there are, the better. It is common to observe segmentation into two or three mindsets (Moskowitz et al., 2020).

It should be noted that due to the limited nature of the BimiLeap software version available at the time of this study, comparisons of mindsets by demographics other than gender and age cannot be made. All demographic questions other than gender and age were assessed in Qualtrics and analyzed in SPSS, there is currently no way to connect lines of data within each subject between the Qualtrics output and the BimiLeap output. Future versions of BimiLeap will allow for the addition of more demographic questions to be added to the BimiLeap survey platform to eliminate this limitation.

\section{Results}

\subsection{Sample Demographics}

All 200 anticipated responses were received for this analysis. The majority white (82.0\%) and female (56.5\%) sample had a mean age of 21.4 years (range 18 - 38) and mostly lived in off-campus apartments in the local area surrounding the University (72.5\%). At the time of survey completion $70.5 \%$ of the sample had not received a positive test for COVID-19 at any time and 58.7\% lived in households that did not experience any residents testing positive for the virus. Further demographics of the samples are in Table 2.

\subsection{Key BimiLeap Results}

The provided BimiLeap data and cluster analysis segmentation information revealed two mindsets existed in this population of undergraduate college students regarding panic buying motivation (See Table 3 ).

\subsubsection{Mindset 1: Focus on Nutrition Content}

This mindset was revealed in the cluster analysis to comprise the thoughts of 98 out of the 200 participants. Elements with resonance were limited to quadrant A 
(focus on nutrient content) including A1 (buying fresh, not frozen), A2 (buying food with a long shelf life), and A4 (buying what is available for ones' diet).

Table 2. Sample characteristics $(\mathrm{N}=200)$.

\begin{tabular}{|c|c|}
\hline Characteristic & $n(\%)$ \\
\hline \multicolumn{2}{|l|}{ Age } \\
\hline 18 to 24 & $193(96.5)$ \\
\hline 25 to 44 & $7(3.5)$ \\
\hline \multicolumn{2}{|l|}{ Race } \\
\hline White & $164(82.0)$ \\
\hline Black or African American & $17(8.5)$ \\
\hline Asian & $17(8.5)$ \\
\hline American Indian or Alaska Native & $1(.5)$ \\
\hline Native Hawaiian or Pacific Islander & $1(.5)$ \\
\hline \multicolumn{2}{|l|}{ Gender Identification } \\
\hline Female & $113(56.5)$ \\
\hline Non-binary & $87(43.5)$ \\
\hline \multicolumn{2}{|l|}{ Class } \\
\hline Freshman & $5(2.5)$ \\
\hline Sophomore & $100(50.0)$ \\
\hline Junior & $75(37.5)$ \\
\hline Senior & $20(10.0)$ \\
\hline \multicolumn{2}{|l|}{ Work Status } \\
\hline Full Time (>32 hours/week) & $12(6.0)$ \\
\hline Part Time (<32 hours/week) & $93(46.5)$ \\
\hline Full Time Student; Not Employed & $95(47.5)$ \\
\hline \multicolumn{2}{|l|}{ Positive COVID-19 Test } \\
\hline Yes, with symptoms & $52(26.0)$ \\
\hline Yes, without symptoms & $7(3.5)$ \\
\hline No & $141(70.5)$ \\
\hline \multicolumn{2}{|l|}{ Household Size } \\
\hline $1-3$ & $121(60.5)$ \\
\hline $4-6$ & $70(35.0)$ \\
\hline 13 or more (Sorority or Fraternity house) & $9(4.5)$ \\
\hline \multicolumn{2}{|l|}{ Household Shopping Responsibility } \\
\hline Myself & $145(72.5)$ \\
\hline One or Both Parents & $38(17.5)$ \\
\hline Significant Other or Other Family Member & $20(10.0)$ \\
\hline \multicolumn{2}{|l|}{ Residence Type } \\
\hline Off-campus Apartment & $145(72.5)$ \\
\hline At Home with Family & $32(16.0)$ \\
\hline Residence Hall & $14(7.0)$ \\
\hline Sorority or Fraternity house & $9(4.5)$ \\
\hline
\end{tabular}


Table 3. BimiLeap data output with cluster analysis segmentation and mindset element identification.

\begin{tabular}{|c|c|c|c|}
\hline \multirow{2}{*}{\multicolumn{2}{|c|}{ Base size (n) }} & \multicolumn{2}{|c|}{ Mindset 1 Mindset 2} \\
\hline & & 98 & 65 \\
\hline \multicolumn{4}{|c|}{ Quadrant A: Nutrient Content } \\
\hline A1 & Buying fresh not frozen & $10^{*}$ & $13^{*}$ \\
\hline A2 & Buying food with a long shelf life & $9^{*}$ & $10^{*}$ \\
\hline A3 & Buying what appears to be healthy & 7 & $9^{*}$ \\
\hline \multirow[t]{2}{*}{ A4 } & Buying what is available for one's diet & $8^{*}$ & $11^{*}$ \\
\hline & Quadrant B: Quantity/Servings/Price & & \\
\hline B1 & Buying as high of a quantity that is available & 0 & 7 \\
\hline B2 & Buying larger or family size packages & -4 & 2 \\
\hline B3 & Getting the most I can within my budget & 0 & 5 \\
\hline \multirow[t]{2}{*}{ B4 } & Grabbing the items I can that are fast and easy to carry out & -5 & 2 \\
\hline & Quadrant C: Personal Feelings & & \\
\hline $\mathrm{C} 1$ & Shopping because I am stressed out & 7 & 6 \\
\hline $\mathrm{C} 2$ & Shopping because I feel out of control of the situation & 5 & $8^{*}$ \\
\hline $\mathrm{C} 3$ & Shopping because I am afraid the stores will run out of food & 6 & 3 \\
\hline \multirow[t]{2}{*}{$\mathrm{C} 4$} & Shopping because I need to feel more secure & 5 & 6 \\
\hline & Quadrant D: Environmental Factors & & \\
\hline D1 & Feeling COVID is not getting better in my area & -7 & -11 \\
\hline D2 & Feeling like I must always be prepared for the worst & -8 & -11 \\
\hline D3 & Worrying that I am at risk for getting COVID-19 & -7 & -12 \\
\hline D4 & rying that my roommates or family will not buy what is really needed & -9 & -14 \\
\hline
\end{tabular}

${ }^{*}$ Coefficients of $\geq 8$ indicate resonance to that mindset.

\subsubsection{Mindset 2: Focus on Need for Self-Actualization}

This mindset was revealed in the cluster analysis to comprise the thoughts of 65 out of the 200 participants. Some of these 65 participants may overlap between the two mindsets since they turned out to be slightly similar in scope. Once again, elements with resonance were limited to quadrant $\mathrm{A}$, but with this mindset, all four nutrient content elements resonated (i.e., buying fresh, not frozen; buying food with a long shelf life, buying what appears to be healthy, buying what is available for ones diet). Within this same mindset the element $\mathrm{C} 2$ had resonance (shopping because I feel out of control of the situation). This was the only resonating element within quadrant $\mathrm{C}$ (focus on personal feelings).

\subsection{Differences in Financial Means and Comfort}

A series of ANOVAs were conducted on the demographic information that revealed there was a significantly higher comfort level $(p<.001)$ with going out and shopping in public during the pandemic among the white students (mean 
$4.47 \pm .82$ out of 5 ) compared to the Black students (mean $3.29 \pm .98$ out of 5 ). The white students also reported significantly higher $(p=.022)$ financial means to buy the food they needed (mean $4.21 \pm 1.02$ out of 5 ) than the Black (mean $3.70 \pm 1.31$ out of 5 ) and Asian (mean $3.58 \pm 1.37$ out of 5 ) students. There were no additional significant relationships between the concepts of financial means and comfort with shopping during the pandemic and any other demographic including gender, work status, or household type.

\section{Conclusion}

Mind Genomics ${ }^{\mathrm{TM}}$ revealed distinct patterns of thinking in this sample when evaluating the potential motivators for panic buying during the COVID-19 pandemic. By using cluster analyses, case segmentation, and ordinary least squares statistical tests, the key segments of thinking were highlighted along with the top elements related to panic buying. Keeping in mind that financial means and comfort with shopping during the pandemic added additional layers of influence to the data, the strongest segment of thinking when buying food centered on "nutrition content" as the highest motivator. This revealed that when college students are faced with a pandemic, there is a large focus on the nutrient content of the food they end up buying. This could be in an attempt to support the immune system and optimize health levels during a time when health is the most important. The COVID-19 pandemic may have caused individuals to be more health conscious; leading them to buy what "appears" to be healthy. Additionally, one's quarantine circumstances may have inspired more health-conscious habits, as people were forced to cook at home more than before. Quarantine and stay-at-home orders may have also provided an environment in which students had more time on their hands to better control their environment and focus on their diet.

No significance or resonance in the B (concern with quantity/servings/price) or D (environmental factors) quadrants of elements may be due to this sample of students not being as affected by stresses of the pandemic than expected. Perhaps students were simply able to buy what they always bought before and were not as affected by supply shortages or fear of shopping as other populations. This sample of college students lacked resonance with most elements related to emotions/personal feelings and all environmental trigger elements which may be related to comfort with online shopping, where supplies seemed to be more available and could be shipped or picked up outside the store. It is important to reinforce that this sample of students knew how to find foods that fit their personal diet. The importance of these discovered mindsets cannot be overstated.

To better enable students to obtain nutritious foods, college health educators can help students build good shopping habits while acknowledging in that education that not all students have the same means to acquire what is needed. College educators and health professionals must set initiatives such as stocking campus food pantries with healthy, nutrient-dense food that is easily accessible 
to all students, so that financial means play less of an influence while supplying students with food targeting their main concern. Additional outlets for healthy food resources could be implemented so if shortages do occur, students have another outlet to go to attain nutritious foods. This may help in easing the fear and influence comfort levels have on motivators behind panic-buying. Because of the pandemic, an effort to appease panic-buyers was made via the implementation of new shopping features such as online ordering, curbside pickup, home delivery services, and increasing contracts with delivery service providers and various technological applications to improve the customer experience while staying at home. The improvement in grocery shopping experience to accommodate new needs of consumers may be aiding in easing fear around shopping that can lead to panic-buying. Successful future marketing strategies and operational initiatives may revolve around how an individual thinks, rather than their demographics (Harizi et al., 2020).

\section{Limitations}

Limitations pertain to the sample itself as well as the statistical platforms that were utilized. The sample of 200 students, while considered a large sample for MG studies, is not fully representative of all LSU students nor all college students in the United States. It should also be noted that since participants were asked to reflect on a time during the height of the pandemic after it had passed (vaccines were made available and stay-at-home orders were lifted at the time of data collection), participant responses may not have been fully accurate. Potential participants were not screened for other variables such as diagnosis of any psychological conditions or pandemic-related trauma. Participants in the sample who may have experienced trauma or were treating psychological disorders may have reacted to the panic buying or this study differently than those who did not experience these issues. While both Qualtrics and BimiLeap generated significant data, there is currently no way to connect the two datasets; therefore, data cannot be matched case-for-case. Additionally, the nature of the BimiLeap platform can be confusing, and since the study was conducted online, researchers were not able to alleviate any confusion should it have arisen during survey completion. The difference in sub-sample sizes by race of the sample may be leading to skewed results related to race and financial status. Lastly, MG was created as a marketing tool for product advancement; this is one of few studies that have attempted to use MG to analyze motivation factors contributing to a particular behavior.

\section{Discussion and Implications}

When studying these possible motivators for panic buying during a pandemic, the data that emerged suggests one mindset is focused just on nutrient content. Therefore, this subset of participants may have been more concerned with obtaining nutritious foods while shopping than anything else going on. Resonance 
with nutrient content elements stood out against the rest of the quadrants. It may be implied that this population is more concerned with nutrient content to put their health at forefront of effort to stay healthy and safe during the pandemic. There was marginal resonance in mindset two with a need for self-affirmation or to feel more in control by panic buying in addition to concern with nutrient content. Fear triggers the need for self-affirmation, driving the mind to seek control, especially in times of crisis. Marginal resonance is seen in quadrant $\mathrm{C}$, concerning personal feelings and emotions as a motivator behind panic-buying. Harizi and colleagues (2020) found among an unspecified adult population resonance with sanitation and supply when shopping during COVID-19. The element is this study that related to supply did not resonate in either mindset among college students. Yuen and colleagues (2020) explored causes (or sources of action) of panic buying while this study examined motives, or ideas that make one want to act. This review of panic buying literature did not explore these common cause themes among a specific population to determine the influence of said causes, including perception of threat, fear of uncertainty, control deprivation, and individual psychological factors. There was no mention of any cause related to nutrient content or personal diet needs.

Financial means and comfort with shopping during the pandemic may have influenced determinants of motivators behind panic-buying. Demographic information highlighted a difference in comfort level between populations of different races, with white students reporting higher comfort levels. The sample also indicated significantly higher financial means for white students than Black students to buy the food they need. These factors add other layers to motivators behind panic-buying that can be further inspected. Results imply that college students focus on food composition when in panic buying situations, and even strive to buy healthy options. Whether or not the threat of COVID-19, prior to the release of the vaccine, led to the nutrient focused mindsets has yet to be definitively determined.

As of 2021 the pandemic is still very much a part of American life. This study could be replicated, with each concept of panic buying during a pandemic (motivators, mindsets, triggers, etc.) explored with increasing granularity. The BimiLeap survey platform will have improvements to its functionality including the ability for researchers to add custom demographic questions that would allow for more statistical comparison of mindsets to the participants personal characteristics. This update would also eliminate the need to use a second survey platform, like Qualtrics, to collect additional data. The convenience and completion speed of this type of study creates an efficient and useful learning tool that can direct a marketing path from respondent to mindset, to immediate presentation of the correctly branded information to a susceptible individual. Now that a source of data is available to help understand college students and panic-buying motivators, improvements can be made to help this often-forgotten population attain the nutritious foods they desire during times of crisis. 


\section{Funding}

This work was supported by the Louisiana Board of Regents Enhancement Grant Initiative-LEQSF (2019-20)-ENH-DE-05 and the LSU Discover Undergraduate Research Grant Initiative.

\section{Acknowledgements}

The authors would like to thank the team at MindCartAI for training on Mind Genomics and the BimiLeap Survey platform. They would also like to thank the LSU Discover Undergraduate Research Program at Louisiana State University for their generous grant support to complete this project.

\section{Conflicts of Interest}

The authors declare no conflicts of interest regarding the publication of this paper.

\section{References}

Bonneux, L., \& Van Damme, W. (2006). An Iatrogenic Pandemic of Panic. BMJ, 332, 786-788. https://doi.org/10.1136/bmj.332.7544.786

Brugarolas, M., Martínez-Carrasco, L., Rabadán, A., \& Bernabéu, R. (2020). Innovation Strategies of the Spanish Agri-Food Sector in Response to the Black Swan COVID-19 Pandemic. Foods, 9, 1821-1841. https://doi.org/10.3390/foods9121821

Clemens, K. S., Matkovic, J., Faasse, K., \& Geers, A. L. (2020). Determinants of Safety-Focused Product Purchasing in the United States at the Beginning of the Global COVID-19 Pandemic. Safety Science, 130, 104894. https://doi.org/10.1016/j.ssci.2020.104894

Dickins, T. E., \& Schalz, S. (2020). Food Shopping under Risk and Uncertainty. Learning and Motivation, 72, 101681. https://doi.org/10.1016/j.lmot.2020.101681

Harizi, A., Trebicka, B., Tartaraj, A., \& Moskowitz, H. (2020). A Mind Genomics Cartography of Shopping Behavior for Food Products during the Covid-19 Pandemic. European Journal of Medicine and Natural Sciences, 4, 25-28.

Hornblower, S., Spawforth, A., \& Eidinow, E. (2012). Panic Buying. The Oxford Classical Dictionary. Oxford University Press. https://doi.org/10.1093/acref/9780199545568.001.0001

Jeżewska-Zychowicz, M., Plichta, M., \& Królak, M. (2020). Consumers’ Fears Regarding Food Availability and Purchasing Behaviors during the COVID-19 Pandemic: The Importance of Trust and Perceived Stress. Nutrients, 12, 2852. https://doi.org/10.3390/nu12092852

Knol, L. L., Robb, C. A., McKinley, E. M., \& Wood, M. (2017). Food Insecurity, Self-Rated Health, and Obesity among College Students. American Journal of Health Education, 48, 248-255. https://doi.org/10.1080/19325037.2017.1316689

Lins, S., \& Aquino, S. (2020). Development and Initial Psychometric Properties of a Panic Buying Scale during COVID-19 Pandemic. Heliyon, 6, e04746. https://doi.org/10.1016/j.heliyon.2020.e04746

Martin-Neuninger, R., \& Ruby, M. B. (2020). What Does Food Retail Research Tell Us about the Implications of Coronavirus (COVID-19) for Grocery Purchasing Habits? Frontiers in Psychology, 11, 1448. https://doi.org/10.3389/fpsyg.2020.01448 
MindCartAI (2021). BimiLeap. https://www.bimileap.com/

Morris, L. M., Smith, S., Davis, J., \& Null, D. B. (2016). The Prevalence of Food Security and Insecurity among Illinois University Students. Journal of Nutrition Education and Behavior, 48, 376-382. https://doi.org/10.1016/j.jneb.2016.03.013

Moskowitz, H. (2018). Mind Genomics for Targeted Marketing. 2018 7th Mediterranean Conference on Embedded Computing (MECO), Budva, 10-14 June 2018, 3-5. https://doi.org/10.1109/MECO.2018.8405952

Moskowitz, H. R. (2012). Mind Genomics: The Experimental, Inductive Science of the Ordinary, and Its Application to Aspects of Food and Feeding. Physiology \& Behavior, 107, 606-613. https://doi.org/10.1016/j.physbeh.2012.04.009

Moskowitz, H. R., \& Martin, B. (2008). Optimising the Language of Email Survey Invitations. International Journal of Market Research, 50, 491-510. https://doi.org/10.1177/147078530805000407

Moskowitz, H. R., Gofman, A., Beckley, J., \& Ashman, H. (2006). Founding a New Science: Mind Genomics. Journal of Sensory Studies, 21, 266-307. https://doi.org/10.1111/j.1745-459X.2004.00066.x

Moskowitz, H., Wren, J., \& Papajorgji, P. (2020). Mind Genomics and the Law. What Is Mind Genomics. LAMBERT Academic Publishing,

Patton-López, M. M., López-Cevallos, D. F., Cancel-Tirado, D. I., \& Vazquez, L. (2014). Prevalence and Correlates of Food Insecurity among Students Attending a Midsize Rural University in Oregon. Journal of Nutrition Education and Behavior, 46, 209-214. https://doi.org/10.1016/j.jneb.2013.10.007

Yuen, K. F., Wang, X., Ma, F., \& Li, K. X. (2020). The Psychological Causes of Panic Buying Following a Health Crisis. International Journal of Environmental Research and Public Health, 17, 3513. https://doi.org/10.3390/ijerph17103513 